\title{
\#Happy: Constructing and Sharing Everyday Understandings of Happiness on Instagram
}

\author{
Jennifer De Paola ${ }^{1}$ · Eemeli J. Hakoköngäs ${ }^{2}$. Jari J. Hakanen ${ }^{1,3}$
}

Received: 7 May 2020 / Revised: 11 September 2020 / Accepted: 1 October 2020 /

Published online: 31 October 2020

(c) The Author(s) 2020

\begin{abstract}
The United Nations' World Happiness Report has ranked Finland as the happiest country for three consecutive years. In this research, we employed thematic analysis to analyze Instagram posts $(\mathrm{N}=650)$ tagged with the hashtag "\#happy" produced by Finnish-speaking users (\#onnellinen in Finnish) during 2018, the first year that Finland gained the title of happiest country.

We found that the representations of happiness constructed on Instagram included seven shared and distinguishable themes: Social relationships, Physical appearance, Free Time, Nature, Success, Pets and Material Things. Drawing from the social representations theory approach, the results revealed a multi-layered structure of the representations of happiness organized around three dichotomies: social-individual, relaxing-pursuing and immaterialmaterial, which were anchored to ideas of "gratitude" (toward something or someone) and "pride" (toward the self). The dichotomy "self-oriented/other-oriented" was interpreted to constitute the themata (underlying structure) of the emerging social representation of happiness.

The paper contributes to the research of everyday knowledge by demonstrating how understandings related to happiness are shaped on Instagram, as well as by proposing a possible strategy for exploring the construction of everyday understandings of different societal issues employing new communication technology platforms containing both visual and textual elements.
\end{abstract}

Keywords Instagram $\cdot$ Social media $\cdot$ Happiness $\cdot$ Everyday understandings $\cdot$ Social representations $\cdot$ Culture and technology

Jennifer De Paola

jennifer.depaola@helsinki.fi

1 Faculty of Social Sciences, Social Psychology, University of Helsinki, P.O.Box 54,

University of Helsinki 00014, Finland

2 Department of Social Sciences, Social Psychology, University of Eastern Finland, Kuopio, Finland

3 The Finnish Institute of Occupational Health, Helsinki, Finland 


\section{Introduction}

"Say cheese!" It is an instruction that countless photographers have given for so long that most people understand the prompt as an alert, seconds before a picture is taken, to smile for the camera. In the era of the Internet and social media, capturing and sharing life's happy moments seem to have become more popular than ever. At the moment of writing, more than 566 million photos marked with the hashtag "happy" have been posted to the photo-sharing social networking service Instagram by English-speaking users alone. By using popular hashtags such as \#happy, individual Instagram users participate in the wider social process of constructing, shaping and circulating everyday understandings of happiness.

Happiness is a complex concept defined and employed in the scientific literature in various ways that overlap with other closely related concepts. Empirical research on happiness has often employed the Subjective Well Being model (SWB) developed by Diener (e.g., 2009), which defines happiness as the result of a high frequency of positive emotions and low frequency of negative emotions, combined with high levels of life satisfaction. Other studies (e.g., Seligman, 2002) have adopted the interpretation deeply rooted in the Aristotelian definition of eudaimonia, which views happiness as stemming from finding the meaning of life.

Overall, in the field of social psychology happiness research has relied heavily on the use of quantitative scales, surveys and questionnaires; however, while these are functional for measuring levels of happiness, they fail when it comes to unpacking what these measurements actually mean for the research participants (Carlquist et al., 2017). Since empirical research on happiness has mainly used predetermined categories for measuring the levels and causes of happiness, there is still very little knowledge about the way people understand and talk about this topic in their everyday life (see De Paola et al., 2020).

We suggest that the concept of happiness is continuously formed through everyday interactions taking place spontaneously in the social arenas encountered in daily life. Such interactions do not happen in a vacuum, but rather they are framed by the particular temporal and local dimensions and social settings which engendered them (Wagner, 2007). For example, Diller (2008) has pointed out the socially constructed nature of the concept of happiness by showing that in textual sources, the dominant preconditions for happiness shifted over the centuries from success to harmonious social relations and pleasurable moments.

In contemporary social arenas, direct verbal communication and mass media are no longer the only contexts in which knowledge is socially constructed. Interactions generated by social media can also convey meanings associated with socially salient concepts. Gibbs et al. (2015) use the term "platform vernacular" to refer to the process of affect and meaning-making through forms of expressions—both verbal and visual—emerging within social media networks. In particular, image-based social media platforms, like Instagram, constitute one of the most important present-day forums in which shared conceptions are constructed, presented and reproduced (Leaver \& Highfield, 2018; Ritland, 2018).

As stated by Reavey (2020), images constitute an essential component of existing cultural resources that people have to make sense of life. Yet, apart from a limited number of studies (e.g., Chen et al., 2017; Suojanen, 2017; Zyl et al., 2019), images have seldom been the target of scientific research on how laypeople understand the concept of happiness. The research has approached conceptions of happiness more often through verbal material, such as open-ended questions like "what is happiness for you?" (e.g., Delle Fave 
et al., 2011; 2016; Uchida \& Kitayama, 2009) and by means of word associations (e.g., Bojanowska \& Zalewska, 2016; Shin et al., 2018, De Paola et al., 2020).

In their study, Chen et al. (2017) instructed participants to take photos of happy moments for a three-week time period, view these pictures and report their mood at the time of viewing them. The results showed that the major themes that participants reported in connection with happiness were "connections with strong ties" and "personal achievements." Similarly, in her study, Suojanen (2017) asked participants to take pictures of what made them happy at work and to elaborate on the meaning of the pictures during followup interviews. The results showed that happiness was represented through five commonly shared categories: work going well, working with friends, the physical environment, doing something that matters, and having a sense of control. However, Suojanen's analysis placed major focus on the narratives produced by participants, as the image production proved to be difficult for the participants due to confidentiality and anonymity issues, as well as challenges with capturing the nature of happiness with a camera.

A more recent attempt at exploring how happiness is visualized (Zieba, 2020) overcomes such issues by employing images marked with the label "happiness" found in the online image bank Shutterstock. The findings revealed that such elements as strong social relationships and belonging, career, enthusiasm and freedom were carefully staged and embedded within polished, bright and minimalistic settings, which were employed to construct images of happiness that appealed to the users of the online image bank. The results showed that images are a valuable source in gauging popular choices made to visually represent happiness, and also how these choices can be informative of specific expectations and normative standards of what being happy should look like. Freitas (2017) advances similar conclusions in reference to how appearing happy is being portrayed in the realm of social media. The advance in digital communication is argued to influence our sense of self, which is deeply affected by the urge to present one's life as happy and flawless at any cost, with possible detrimental consequences on social media users' well-being (Freitas, 2017).

While there is a growing corpus of literature exploring the many connections between happiness and social media in terms of the effect of digital technology on people's wellbeing (Helliwell et al., 2019; Mackson et al., 2019; Munzel et al., 2018), the research has less often (e.g. Li \& Kim 2019) focused on how the textual and visual flow of social media posts about happiness are shaping the very idea and understanding of happiness itself. For example in their study, Li and Kim (2019) performed a content analysis of photography posts tagged with the hashtag \#happy and/or \#happiness, showing that photos centered on physical appearance, relationships and success are often associated with these hashtags. Closely related to this endeavor is also Rieger and Klimmit's study (2019), which explored the contents of eudaemonic communication employing inspirational memes found on Instagram. The results showed that topics of inspiration and meaningfulness included social relationships and the ability to cope with hardships. These results inform about what topics are associated with the abstract concept of eudaimonia, starting from "found" material produced by social media users without the intervention of the researchers.

\section{Social Representations of Happiness}

In this study, social representations theory (SRT) (e.g., Moscovici, 1984) is used as a theoretical framework to analyze the visual representations of happiness among Finnish Instagram users and to explore the shared understandings of happiness in these posts. Social 
representations organize everyday social actions and communications, functioning as interpretation systems which enable people to coexist in complex social arenas (Moscovici, 1984). According to Moscovici (1973, xvii), social representations have two main functions: by providing a code for classifying and naming various phenomena, they make it possible to meaningfully communicate with others and to orient to the social world. The type of social interaction in which social representations are constructed is tied to the communicative platforms: printed newspapers provide different possibilities for discussion than online forums. Duveen (2008) has suggested that social representations theory should better explain new features of social interaction in digital platforms. Buschini (2016) has presented the concept of "effusion" to describe social communication in new media environments characterized, for example, by the increased importance of visual communication, as well as other-oriented behavior (i.e., sharing).

Social representations theory highlights the inseparability of the individual and social in knowledge formation in which people are not passively mirroring shared conceptions but actively participating in their negotiation (Moscovici, 1994). Social media photography demonstrates this core idea of the theory: when people are taking a photograph and making their visual choices, they use their agency and present their subjectivity (Zappavigna, 2016), but at the same time these choices are publicly affected by socially formulated preferences of what is considered appropriate, compelling or understandable to share. When the user decides to attach a popular hashtag to their visual presentations, the product is participating in social meaning-making (Gibbs et al., 2015).

Social representations are formed through two main processes: anchoring and objectification. Anchoring involves locating the strange or foreign within the familiar, specifically through classifying and naming unknown objects using already known categorizations. In the process of objectification, something abstract or elusive is transformed into something more concrete and tangible (Moscovici, 1984). Verbal communication is not the only way social representations are shared; visual material can also convey meanings associated with salient concepts and even crystallize the iconic aspect of representation (de Rosa \& Farr, 2001). The role of visual images has recently aroused the interest of researchers. For example, Boulanger (2019) has noted how aesthetics can act as a dialogical encounter in the process of objectification, and Hakoköngäs and Sakki (2016) have demonstrated how the process of anchoring can be identified by paying attention to textual supplements, like captions within visual material.

Since social representations are complex and dynamic, an additional central element of the theory is the concept themata (Moscovici, 2001), which can be described as the dichotomies or oppositional pairs (e.g., clean/dirty, beautiful/ugly) underlying everyday thinking and language around a certain concept (Marková, 2000; 2003). Liu (2004) argues that the theoretical concept of themata allows observation of the origin, structure and dynamics of social representation, including its pragmatic manifestations. Pragmatic manifestations drawn from themata are dependent upon both the objectification and anchoring described above (Liu, 2004). In the material of the present study, for example, the concept of happiness is objectified with Instagram posts (typically photographs), which are anchored by means of hashtags and captions referring to the intended meaning of the visual image. Posts participating in the social communication on the social media platform demonstrate a pragmatic manifestation of the representation.

Originally conceived as a theoretical approach underlining the way in which people deal with threatening or unfamiliar concepts that penetrate the public discourse (Moscovici, 1984), SRT has also been employed in the study of other topical concepts that are not necessarily threatening or unfamiliar, but which have been taken up for discussion 
(Hakoköngäs \& Sakki, 2016). Visual representations of happiness circulated among Finnish-speaking social media users are particularly interesting, since Finland has been ranked as the happiest country in the world for three consecutive years (e.g., Helliwell et al., 2020), and happiness has become a socially salient concept in Finland.

With more than a billion daily engagements (Instagram, 2020), Instagram provides an opportunity for analyzing the social meaning-making about happiness. Closely connected to this view is Zieba's (2020) observation that the ways in which happiness is visually represented both repeat shared conceptions and construct them. Gaining insight into how happiness is represented on a social media platform matters, because lay theories of happiness can have an impact on how happiness and life itself are experienced (Koo \& Suh, 2007).

\section{Instagram: A Present-day Arena for Social Knowledge Formation}

Instagram is a social media application that allows users to upload photos and videos to the service and share them instantly with other users. The posts can be viewed, liked and commented on by one's followers (in the case of a private account) or by any Instagram user (in the case of a public account). In addition, users can also browse other users' content by tags, searching for interest-specific or trending content. At the time of writing and since the application was launched in October 2010, a total of 20 billion photos have been shared.

Empirical studies have increasingly turned to the prolific source of so-called "found" research materials provided by social media platforms (Cortese et al., 2018). However, research focusing on photo-sharing services has mainly focused on users' behavior dynamics (e.g., Mackson et al., 2019), whereas the everyday understandings of socially salient issues constructed through images remain largely unexplored, with the exception of a limited number of studies (e.g., Ritland, 2018; Leaver \& Highfield, 2018). According to Miles (2013), as a social arena Instagram has several distinguishable characteristics compared to other social media platforms. For example, material uploaded to Instagram has a longer shelf life than posts on similar social media (e.g., Snapchat), and Instagram's focus on image sharing instead of conversation makes its upkeep easier. Most importantly, Instagram was created specifically for mobile devices, and this portability has allowed users to share posts of the actual moment they are experiencing.

Notwithstanding the nature of the present moment underlying the sharing of images, Instagrammers do not simply share a random snapshot without thinking of the potential impact and reach of their post. Instead, they often intentionally stage what they feel is the best possible representation of an interesting life, which lacks boredom, sadness and failure (e.g., McLean et al., 2015). In her study on the visual representations of happiness found in an internet image bank, Zieba (2020) points out how stock photography can hardly be considered a faithful documentation of everyday life, but it is nevertheless interesting in that it provides a better understanding of the choices the image bank itself makes when categorizing images under the label "happiness," based on the clear intent of appealing to the portrayal of happiness endorsed by potential subscribers/buyers. For this reason, we agree with Buckingham's (2009) warning to refrain from considering visual data as an accurate or more genuine representation of people's attitudes or beliefs around a specific issue. Thus, visual methods should not be seen as a "means to gain privileged access to what people 'really' think or feel" (Ibid., p. 635). Based on these observations, Bourdieu's description of photographic practice as "art which imitates art" seems to be of timely relevance when exploring photo-based social media: "photographing is not just a means to capture reality, but it is only ever the result of arbitrary selection" (Bourdieu, 1990, p. 73). In other 
words, while conclusions on peoples' "happiness" cannot be drawn from Instagram posts, we may consider them as contributions to the social discussion constructing, disseminating and reflecting the social conception(s) of happiness.

\section{Aims of the Present Study}

In the present study, we employed user-generated material from Finnish Instagram users to analyze how happiness is represented in the context of image-based social media.

To the best of our knowledge, everyday understandings of happiness (and closely related concepts) in visual contexts have received very limited attention (Zyl et al., 2019). Words are hardly the only way in which everyday knowledge is created and shared, and visual material can convey essential meanings associated with salient concepts (Sakki, 2010). The ability of photographs to concretize abstract phenomena and the ease of sharing such material on social media make images key elements in the production of everyday conceptions (Joffé, 2008; Hakoköngäs et al., 2020). In this study, therefore, we aim to explore how the visual and textual contents of Instagram posts combine in the construction of everyday understandings of happiness in digitally mediated communication. In pursuit of this goal, three research questions were posed:

What are the main contents on the Instagram posts marked with the hashtag "happy" in Finland? How is happiness made tangible (objectification) and how is it given meaning (anchoring) in these posts? And how is the social representation of happiness on Instagram organized (themata)?

\section{Material and Method}

\section{Material and the Context}

The research material consisted of photos $(\mathrm{N}=650)$ and related hashtags and captions posted by Finnish-speaking Instagram users between March and October 2018. The Instagram posts included in the current study were selected on the basis of the hashtag "happy" being present in the post. The term "hashtag" refers to one or more keywords preceded by the hash symbol (\#). The purpose of hashtags in social media is to identify, classify and categorize messages in relation to a specific topic. Simultaneously, they communicate contextual cues to give more depth to a caption or photo.

The data collection was limited to posts marked with the hashtag "happy." At the time the data was collected, \#happy (onnellinen in Finnish) had been used 138,168 times by Finnish-speaking Instagrammers. Compared to \#onnellinen, other hashtags connected to the concept of happiness (including "happiness" as a noun) were less popular. For example, \#onnellisuus (happiness) occurred 26,673 times; \#ilo (joy) 105,867 times; \#iloinen (joyous) 28,023 times; and, finally, \#hyvinvointi (well-being) 87,065 times. This reflects the more common usage of the adjective "happy" in everyday spoken language compared to the noun, which, particularly in Finnish language, presents more abstract connotations. Along with the photo the and hashtag "happy," other hashtags used, as well the caption of the post, constituted part of the material on which we based our analysis.

The images were gathered in 2018 during four months in spring and in autumn in order to get a more balanced picture of different ways to visualize happiness. As the whole of Finland lies in the boreal zone, increasing light and the awakening of nature have more 
emphasis in the spring than in autumn. Three big seasonal celebrations (Easter, Mother's Day and Graduation Day) were excluded from the material, as they would reduce the themes of the post to the respective topics of the celebrations (e.g., graduation).

Only publicly posted and publicly shared material was used for the study. However, when dealing with social media it is important to consider that users may not be aware that their posts are public or realize the extent of their distribution. In accordance with the guidelines of the Finnish Advisory Board on Research Integrity, the users' anonymity was guaranteed throughout the process of data collection, storage and, finally, writing the report.

\section{Analytic Procedure}

We employed thematic analysis as principal method of investigation, which can be described as "a method for identifying, analysing and reporting patterns (themes) from within data" (Braun \& Clarke, 2006, p. 79). The central concepts of SRT-objectification, anchoring and themata-were investigated throughout the analysis of the present study as separate processes to systematize the identification of different elements of the posts (visual manifestation, meaning and underlying structure).

The analytic procedure followed a six-step process (for a similar approach, see Hakoköngäs et al., 2020; Zieba, 2020). The first step, Familiarization with the data, was achieved by going through the gathered 650 Instagram posts. The second step, Generation of initial codes, involved giving a label (for example, "Children," "Adults," "A Group of people") to the posts inductively in accord with our objective to identify the contents of the posts with the hashtag \#happy. In this stage, the first and second author of this paper labeled posts independently. The third step was Searching for themes, which involved classifying the initial labels under broader themes (for example, the initial labels "Children," "Adults" and "A Group of people" were clustered together as an initial theme called "People"). The second and third steps included the identification of objectifications (i.e., making abstract tangible) and the iconic aspect of representation (de Rosa \& Farr, 2001).

The common principle in this iterative coding process was to code the Instagram posts on the basis of their most dominant meaning. Visual objectification may carry multiple meanings, and often the textual element complements the intended meaning (Hakoköngäs et al., 2020). In the case of this study, the hashtags and captions added by the Instagram users to accompany the post served as interpretative keys for disambiguation. For example, in a post depicting a woman and a young boy on a road trip, the caption reads simply "Family holiday [Perheloma]," and it is followed by the hashtags \#motherandson[äitijapoika], \#love[rakkaus], \#nothingismoreimportant [mikääneioletärkeämpää], implying that happiness is associated with social ("Family holiday") and emotional ("love") connectedness between family members ("motherandson"), on the basis of which the post was classified under the initial theme "Family."

After constructing the initial themes, the process was followed by the fourth step, Reviewing themes, which involved refining and defining the classification of posts resulting from the previous steps of analysis. In this phase, the two coders compared their interpretations and the posts for which an interpretation could not be agreed upon were placed under the category "Other" $(\mathrm{N}=41)$. The fifth step, Defining themes, involved naming the themes and corroborating their definitions. In practice (during the fourth and fifth steps, for example), the images previously labeled under the themes "People" and "Family" were grouped together under a common theme, which was named "Social relations." 
Finally, the sixth step, Producing the report, involved interpreting and reporting the final themes, describing interconnections between the themes and interpreting the organization (themata) of the social representation conveyed through \#happy posts on Instagram. We found the hashtags accompanying the posts to be especially useful when characterizing and naming the dichotomies constituting the themata.

\section{Results}

\section{Thematizations of \#Happy}

To answer the first research question What are the main contents on the Instagram posts marked with the hashtag "happy" in Finland?, the thematic analysis shows that the posts included seven distinguishable common themes, which we named according to the characteristics that best described the commonalities found in them: Social relationships, Physical appearance, Free Time, Nature, Success, Pets and Material Things. These themes are presented in Table 1.

In general, the visual part of the analyzed posts was characterized by a mixture of casual yet visually sophisticated design, where attempts at both authenticity and attractiveness can be found. In the present context, authenticity refers to a visual form reflecting an attempt to create a glimpse of everyday life without emphasizing the use of filters or editing in the photographs. Attractiveness refers to the visual form of posts seeking to arouse interest in the message, inviting Instagrammers to engage with the post (for example, by adding a like or comment).

To answer the second research question How is happiness made tangible (objectification) and how is it given meanings (anchoring) in these posts?, we describe the aforementioned themes of the Instagram posts by using the analytical concepts of SRT. Hashtags and captions written originally in Finnish are translated and presented in square brackets [].

\section{Social Relationships}

This theme included photographs depicting happiness in the context of social relationships $(\mathrm{N}=150)$. The photographs typically objectified happiness by presenting couples (a romantic relationship), friends in a group, and parenthood (especially pregnant women or very young children). These images were interpreted to visually craft the idea

Table 1 Themes in Instagram posts containing \#happy

\begin{tabular}{ll}
\hline Themes & $\mathrm{N}$ \\
\hline Social relationships & 150 \\
Physical appearance & 108 \\
Free time & 103 \\
Nature & 75 \\
Success & 72 \\
Pets & 54 \\
Material things & 47 \\
Other & 41 \\
Total & 650 \\
\hline
\end{tabular}


of emotional connectedness between the Instagrammer and their loved ones through different compositions: for example, in group (or couple) selfies, subjects often appeared to look into the camera while smiling and tilting their heads toward each other. In other photos, the image depicted only one person, while the hashtags or caption referred to the social nature of the happiness: for example, \#theworldsmostloved [maailmanrakkain], \#Ilove [rakastan] and "I am \#happy to have so many beloved people around me [Olen \#onnellinen että minulla on niin paljon rakkaita ihmisiä ympärillä]." Based on the analysis of the hashtags accompanying the images objectifying happiness in social contexts, this theme was anchored most often to love and gratitude (\#grateful [kiitollinen], \#blessed [siunattu]). Anchorings in this case gave meaning to the visual presentations: people were depicting their significant relationships and claiming that these bonds made them feel happy.

\section{Physical Appearance}

The theme Physical appearance $(\mathrm{N}=108)$ appeared in posts in which the Instagrammer $\mathrm{him} /$ herself was the main subject in the photo. The material analyzed contained a wide variety of selfies, including close-ups of the Instagrammers and mirror selfies, where the subject attempted to show some part of their body to the best advantage. In these images, the visual composition appeared to enhance the salience of the Instagrammer's face or body. This was accomplished mainly by means of filling the frame with the subject's face/ body or by staging the selfie in a mundane setting, such as a car seat or bathroom, drawing the attention of the viewer to the main subject and away from the backdrop. The captions and hashtags also made clear references to physical attributes and features, like make-up or hair color: for example, \#browneyes, \#redhair or "just went to hairdresser" [kävin just kampaajalla]. The hashtag "finnishgirl," which was very popular in this theme, was interpreted to represent a socially shared meaning used specifically on Instagram and anchoring photographs to Finnishness. While the theme Social Relationships was anchored to gratitude and feelings of being blessed, Physical appearance can be interpreted as anchored to more material features, such as beauty or handsomeness.

\section{Free Time}

The posts in this theme $(\mathrm{N}=103)$ comprised representations of the user enjoying their free time, including time off from work, evenings after work, weekends or public celebrations. These images objectified Free Time with such symbolic elements as hot drinks and other beverages, common leisure-related venues like swimming pools and hotels, and textual references indicating that the Instagrammer was not working (e.g., \#dayoff, \#holiday). In these images the symbolic representation of free time was often the primary subject of the photo. The Instagrammer was often absent from the frame or only a specific portion of their body was shown (for example, a hand holding a cup); feet by the pool were very common. These elements served as the symbolic representation of free time and emphasized the association that happiness and free time are connected. Some of the images were anchored in hashtags to gratitude or the feeling of being blessed (\#grateful [kiitollinen], \#blessed [siunattu]), the ability to enjoy free time (\#metime [omaaika]) and, more specifically, being able to enjoy the moment, conveyed through the use of hashtags such as \#momentslikethese. 


\section{Nature}

The posts included in the theme Nature $(\mathrm{N}=75)$ objectified the concept of happiness through the depiction of various nature landscapes (especially Finnish forests) or through details of nature (e.g., wildflowers, leaves) and various references to the climate and season. In addition, these images were characterized by bright and vibrant colors, making the sunlight itself a common feature in most of the images. The compositions of the photos varied from picture to picture, from the natural element itself being the subject of the photo to images where the Instagrammers were the main subject and nature acted as a backdrop, portraying the idea of nature as a dimension which includes both the landscape and the viewer as parts of a whole. In these portraits, the Instagrammer was often looking away from the camera and toward a sunset, forest or lake, inviting the viewer to direct their gaze at the natural element which had prompted the image composition. Objectifications of nature were anchored to two distinct yet interrelated themes. On the one hand, users anchored nature to peace, calm and even therapeutic properties, such as \#peace [rauhaa], \#naturepeace [luonnonrauha], \#restforsoul [sielulepää] and \#naturetherapy [luontoterapia]. On the other hand, nature was anchored to the geographical peculiarity of Finland and to Finnishness, positioned in the wider virtual context of Instagram. Examples of the latter anchoring process were hashtags like \#visitfinland, \#finland and \#finnishnature. An ulterior anchor to nature widely shared in the material was beauty, such as \#beautiful [kaunis]. In the posts, the aforementioned properties of nature were connected to or paralleled with the idea of happiness born out of the natural environment.

\section{Success}

The theme Success $(\mathrm{N}=72)$ included several sub-themes, such as work life (e.g., a promotion or succeeding in getting a new job), education (e.g., graduating), hobbies (e.g., winning a sports competition) or health (e.g., overcoming an illness). Some photographs also referred to someone else's achievement (for example, graduation of the Instagrammer's child). The objectifications of success often contained portraits, flowers, food and drink or other traditional symbols of victory (e.g., a diploma or medal). The compositions in these themes were usually carefully staged: flowers, celebratory foods and drink and eventual milestone certificates/cards were commonly arranged to achieve a harmonious whole that told the viewer "the story" behind the successful moment being celebrated. Alternatively, compositions included the Instagrammer as the main subject in the act of holding the symbols of victory. These portraits were typically half to full-length, with the subject either smiling or engaging in a power pose (or both) while looking directly into the camera. These objectifications associated the idea of happiness with success. Objectifications were anchored with two subthemes. The first theme referred to achieving one's dreams and aspirations, such as \#dreams [haaveet] or \#dreamjob [unelmaduuni], anchoring the meaningfulness of the achievement to the immediate present or future. The second theme anchored success to the idea of satisfaction stemming from hard work: for instance, \#longday [pitkäpäivä], \#longdayover [pitkäpäivätakana] or, more explicitly, \#studyhard. In addition, a shared point of anchoring throughout the main theme was the feeling of pride stemming from achievement: the various hashtags ranged from \#proud [ylpeä] to \#soproud [niinylpeä]. 


\section{Pets}

The category of Pets $(\mathrm{N}=54)$ especially featured pictures of domestic animals (e.g., cats, dogs, rabbits) and, more rarely, horses. It seems that the hashtag \#happy was primarily used to refer to the Instagrammers themselves enjoying time spent with their pets (in pictures depicting Instagrammers with their pets), as well as the pets themselves (in pictures where the pet was the main subject). In the former, the Instagrammers were most commonly depicted directing their gaze toward their pet, rather than toward the camera. In the latter case, the Instagrammer was often the voice of the pet, which, according to their owner, was feeling happy. The anchoring mechanism in this category was commonly made visible through the use of hashtags indicating the visual pleasantness of the pet, like \#cute [söpö] or \#sweet [suloinen] and similar variations. Another anchoring mechanism in the theme referred instead to the idea of ownership, with hashtags like \#mypet [minunlemmikini] or hashtags identifying the specific breed (e.g., \#jackrussell, \#germanshepherd).

\section{Material Things}

The images $(\mathrm{N}=47)$ as well as hashtags and captions in posts depicting Material Things represent the idea that the possession of a specific object (for example, a musical instrument, clothes, a vehicle, an apartment) is connected to happiness. The objectifications were anchored especially to the feeling of pride derived by being in possession of something brand new, as seen through the use of hashtags like \#newhome [uusi koti] or \#newcar [uusauto]. The material possessions were also anchored to the immediate pleasure experienced following the purchase (e.g., \#enjoylife or \#joyful [iloinen]), as well as the context of receiving a present and being grateful: for example, \#thankyou [kiitos], \#thankful [kiitollinen] and \#solucky.

\section{Themata and Dichotomies of the Social Representation of Happiness in Instagram}

To recapitulate, we used thematic analysis to examine the contents of selected Instagram posts marked with \#happy. This process resulted in the aforementioned seven themes, which we further analyzed using SRT conceptual tools to detect explicit manifestations (objectifications) and meaning-making processes (anchoring) connected to the posts.

Next, to answer the third research question How is the social representation of happiness on Instagram organized (themata)?, we analyzed the interconnections between the seven themes. We initially identified dichotomies based on the description of the seven themes, finding three main ones: social-individual, relaxing-pursuing and immaterial-material. These labels are appended to the dichotomies to help the reader better understand the underlying structure of the data. The social-individual dichotomy, for example, does not refer to the process by which the representation is engendered (which is inevitably always social) but aims to reflect the main content of the post.

The first dichotomy, social-individual, defines the contrast between social relationships and the self-image of the individual as constituent of a shared idea of happiness. In this dichotomy, relations to other people, on the one hand, and self-focused representations, on the other, are presented as constituting principles of "happiness." The second dimension, relaxing-pursuing, describes the contrast between the two different ways 
of spending time as constituents of happiness. On the one hand, spending time with loved ones, being off work and being on a holiday are represented as "happiness." On the other, getting a promotion or new job, or competing in sports, comprises elements that illustrate a representation of happiness linked to using one's time in a productive, industrious and competitive way. The third dichotomy, immaterial-material, constructs the idea of the importance of physical ownership over something, on the one hand, and collective goods which cannot be possessed, on the other. If the concept of happiness is often made concrete through posts illustrating ownership of material goods (e.g., clothes, an apartment, accessories), aspects of life which "cannot be purchased" (e.g., nature, warm weather, a sunset) present a strong link to the idea of immaterial constituents of happiness.

After analyzing the interconnections in relation to the seven themes based on their description, we deepened our analysis by focusing specifically on the main anchorings previously identified in connection with the themes: gratitude, pride, blessedness, beauty and joy. The first two anchorings can be interpreted to constitute an elementary antinomy (thema) of the social representation of happiness, namely, self-oriented versus other-oriented: "gratitude" (toward something or someone) as other-oriented; "pride" (around the Instagrammer's own performance or image) as self-oriented. Joy and beauty were interpreted to represent general positive connotations related to happiness, and their meanings could not be analyzed further on the basis of the present data. The structure of the social representation is summarized in Table 2.

\section{Discussion}

The present study sought to answer three distinct—yet interrelated-questions: What are the main themes of the Instagram posts marked with the hashtag "happy" in Finland, the country ranked as the happiest in the world? How is happiness made tangible (objectification) and how is it given meaning (anchoring) in these posts? How is the social representation of happiness on Instagram organized (themata)?

Thematic analysis showed seven main thematizations within the posts marked with the hashtag "happy": Social Relationships, Physical appearance, Free Time, Success, Pets, Nature and Material Things. These were anchored primarily to gratitude and pride. We detected three dichotomies in these themes: social-individual (Social Relationships vs. Physical appearance) relaxing-pursuing (Free Time vs. Success) and immaterial-material

Table 2 Objectifications, dichotomies, anchorings and themata of the social representations of happiness

\begin{tabular}{llll}
\hline Thematization of objectifications & Dichotomies & Anchorings & Thema \\
\hline Social relationships & Social-Individual & Gratitude; Blessedness & Self-oriented \\
Physical appearance & & Beauty; Pride & Other-oriented \\
Free time & Relaxing-Pursuing & Gratitude; Joy & \\
Success & & Pride & \\
Pets & Immaterial-Material & Joy & \\
Nature & & Beauty; Therapy & \\
Material things & & Gratitude; Pride & \\
\hline
\end{tabular}


(Nature/Pets vs. Material Things). Additionally, drawing from the methodological framework provided by social representations theory, we interpreted the anchorings to "gratitude" (toward something or someone) and to "pride" (toward the self) as constituting the underlying organizational structure (themata) of the emerging social representation: "self-oriented/other-oriented."

As regards the first research question, our analysis revealed that the seven main themes were commonly shared. Thus, it is reasonable to suggest that there is in fact a shared representation of the concept of happiness among Finnish-speaking Instagram users. The objectifications in the analyzed posts reflect the iconic aspect (de Rosa \& Farr, 2001) of social representation by crystallizing the abstract concept of happiness, for example, with images depicting Social Relationships or Physical appearance-themes that have also been identified in other studies analyzing visual representations of happiness (Zieba, 2020). The other posts, especially those objectifying happiness with lakes and forests (i.e., Nature) can be particularly iconic for Finnish people. Similar objectifications are shown to represent Finnishness also in social media rhetoric in which images of wild nature are associated with Finnish identity (Hakoköngäs et al., 2020). In the context of posts related to happiness, the nature may as well be connected to national identity as well as the idea of close relation between Finns and nature.

In regard to our second research question, we proposed that in order to understand how happiness is made tangible (objectification) and how it is given meanings (anchoring) in these posts, we have to take into account both the communication and aesthetic norms of social media, as well as the specificity of Finnish-speaking Instagrammers. In addition, we felt it is important to consider how scientific notions related to happiness and well-being may have trickled down into the wider public discourse, influencing and shaping commonsensical notions of happiness, a process defined in SRT terms as interaction between scientific (or reified) and consensual (common-sense) universes. For example, the importance given to Social Relationships accords with the previous literature on happiness, which has emphasized the role of social relationships in happiness (e.g., Veenhoven, 2012), as well as with previous research looking at visualizations of happiness (Chen et al., 2017; Suojanen, 2017; Zyl et al., 2019). In contrast, Physical appearance represents a rather different perspective of happiness, which we propose is shaped and conditioned by the idea of individuality as a trait to be cherished. The objectification of happiness in this theme was predominantly characterized by the use of selfies, which is perhaps unsurprising, considering how scholarly literature has already described the widespread use of selfies as a pervasive phenomenon in modern digital culture (e.g., Tiidenberg \& Gómez Cruz, 2015). As self-presentation can adjust to different social contexts (Bertoldo \& Castro, 2019) and be molded according to the characteristics of specific audiences (Goffman and Idea, 1959), we suggest that Instagrammers represent the abstract concept of happiness by representing themselves. In this sense, especially the theme Physical appearance connects to the relevance of aesthetic norms and physical attributes in the construction of social representation (Boulanger, 2019).

The meanings attached to the theme Free Time were strongly connected with immaterial or abstract elements anchored through the use of hashtags such as \#momentslikethese, resonating with Western culture's popular discourse of conscious living and happiness derived from small everyday moments, like enjoying a cup of coffee in the morning (see Hurley \& Kwon, 2012). In contrast with the idea of relaxing and breaking out of one's routine, which dominated the theme Free Time, the theme Success reflects the popular Finnish notion that "hard work is the key to fortune/happiness" [Ahkeruus kovan onnen voittaa] and that "The beginning is always difficult, but in the end stands thanks" [Alku 
aina hankala, mutta lopussa kiitos seisoo]. While happiness studies have questioned the relationship between success and happiness (Lyubomirsky et al., 2005), images where happiness is objectified through symbolic basking in the glory of success suggest that in the realm of everyday thinking, these two issues are related. The finding is rather unsurprising, considering that on social media people prefer to share about successful experiences rather than failure (Reinecke \& Trepte, 2014).

Differently from Success, the theme Nature could be a way of objectifying an idea of happiness that is more specific to the Finnish culture than to the wider context of Instagram. As recently noted by Tyrväinen et al. (2019), in Finnish culture trees and forests in particular are widely perceived to have properties that enhance health and well-being. This cultural understanding of being happy in association with spending time in nature resonates with the current public discourse and local marketing strategies in relation to the connection between nature and happiness. For example, the campaign Rent a Finn, launched in 2019 by the government-funded company Business Finland, organizes nature trips with local Finns who act as "happiness guides" for visitors interested in finding happiness through nature: "Our secret is in our nature. When others go to therapy, Finns put on a pair of rubber boots and head to the woods (Rent a Finn, 2019).

Similarly to Nature, pets and especially dogs hold a special position in the everyday life of Finns and are often considered part of the household. This is a tradition deeply rooted in Finnish culture and folklore: for example, giving pets a first name is a widely known practice which can be observed already in the Finnish national epic Kalevala (Koski \& Bäcklund, 2015). Even though the objectifications of the theme Nature visually resembled the theme Pets, the anchorings in the two themes were different. The most common way in which Instagrammers anchored the idea of happiness with Pets is with the feeling of tenderness elicited by the "cuteness" characterizing their pet, on the one hand, and the idea of the pet as an item which could be owned, on the other. In connection to the idea of happiness stemming from possession, the theme Material Things objectified the concept of happiness with images of new objects of varying monetary value. Material Things have been shown to be anchored not only to feelings of pride, but also gratitude toward their source. Apparently, the popular saying that "money doesn't buy happiness," while resonating with happiness studies that have explored the relation between money and happiness (Diener \& Oishi, 2000), does not take into account the pleasure of sharing on social media one's contentedness about a new purchase (or gift).

Finally, our third research question sought to explore the underlying organizational structure of the social representations, looking at possible dichotomies in the textual and visual discourse around the concept of happiness on Instagram. Our results showed that the seven thematizations were anchored mainly to the features of gratitude, blessedness and pride, which constitute the underlying organizing principle (thema) of the representation we have named "self-oriented/other-oriented." This thema reflects the principal dilemma characterizing the social representation of happiness, similar to the thema of "having/ being" characterizing the Chinese conception of Quality of life (see Liu, 2004). While in Chinese society this dilemma reflects the social transition from a socialist economy to a market economy, in Finland the roots of the thema are not so easily traced. Balancing between individuality and collectivity may reflect the long transition from an agrarian-collectivistic society to industrial and post-industrial ones. Unlike in many other European countries, this development happened rather late in Finland, starting in the late 1960s.

Moloney, et. al, (2005) have argued that the existence of such contradictions does not need to be interpreted as the existence of two or more different social representations. On the contrary, Moscovici and Vignaux (1994), as well as Marková (2000), argue that 
oppositional categories or antinomies are an elementary feature of socially constructed conceptions. In fact, contradictions and tensions characterizing a discourse around a topic serve the function of maintaining momentum in the discussion, thus preserving its saliency and allowing individuals to take functionally different positions on the same topic (Moloney, et. al, 2005).

For example, an individual's choice to share a photograph on a social media platform is in essence a communication act between the sender and the (imagined) audience. Several studies (e.g., Moscovici \& Vignaux, 1994; Liu, 2004) have emphasized the historically embedded nature of themata. As far as we know, the history of the Finnish word "happy" (i.e., onnellinen) has not been studied, but analysis of the English word "happy" indicates a transition that is parallel to the thema found in the present study. According to Diller (2008), the meaning of the word has shifted from external conditions (other-oriented) toward internal conditions (self-oriented). It is not necessary for the newer meaning to replace the previous one, but in the present study they can be interpreted in the Finnish context as constituting the dynamics of the conception of happiness.

\section{Limitations and Future Directions}

There are three main limitations of our study which we would like to address. First, the study was based only on data generated by Finnish-speaking Instagram users. It would require an intercultural comparison to determine if happiness is represented in a similar manner in other contexts. A second limitation is represented by the age distribution among Instagram users, which compared to other social media platforms leans heavily toward younger people (18-29 year olds). An interesting future possibility would be to collect visual data from older age groups on a different platform (for instance, Facebook).

At a wider level, a third limitation stems from our exclusive focus on user-generated data collected on Instagram, which is just one of many image-based platforms found in the present-day sphere of social media. It is important to restate how the aims of our study could be extended to other popular social media platforms (for example, Facebook or Tumblr). However, concerning the limitations surrounding the generalizability of our findings, it is to be noted that SRT is by definition a theoretical approach of specific group members and communities (Duveen \& Moscovici, 2000); thus, the generalization of our findings to society at large is an endeavor that extends beyond the aims of the current study. To sum up, future studies comparing a variety of social media platforms and being more inclusive of different linguistic groups are required in order to refine the development of innovative tools to follow the social formation of knowledge in the era of social media.

\section{Conclusion}

Our study endeavored to illustrate how Instagram (and similar platforms) can be used as a user-generated source of material to understand how everyday knowledge on socially salient concepts, such as happiness, are formed and circulated. We claim that such everyday understandings of happiness are worth being explored, since laypeople's theories about substantial topics can have an impact on the way they make important decisions in life.

In addition to illustrating the way in which happiness is objectified, anchored and organized on Instagram, the findings of the present study present theoretical implications for the scientific study of the current ways in which knowledge of happiness (and other similarly salient concepts) is socially formed. The increased importance of social media has 
raised the need for new modalities of communication expressed in digital technologies (e.g., Duveen, 2008). Buschini (2016) has presented the concept of "effusion" to describe social communication in new media environments characterized, for example, by visual communication and sharing. Inspired by Duveen's and Buschini's ideas, the present study has sought to develop the theory through an empirical example of how social conceptions are shaped in social media discussions relying mainly on visual messages.

Combining thematic analysis (Braun \& Clarke, 2006) with theoretical elements of SRT (Moscovici, 1984) provides a methodologically and theoretically effective toolkit for addressing not only textual but also visual aspects of everyday understandings of happiness circulated on social media. Our findings suggest that such analysis should not solely rely on the tangible visualization of the topic and textual notes. The distinctive characteristics of social media, aesthetics, and elements specific to linguistic and cultural contexts are important to take into account to reach a deeper understanding of the underlying meaning of social communication in current social arenas.

Funding Open access funding provided by University of Helsinki including Helsinki University Central Hospital.

\section{Compliance with Ethical Standards}

Conflict of Interest The authors have no conflicts/competing interests to declare.

Open Access This article is licensed under a Creative Commons Attribution 4.0 International License, which permits use, sharing, adaptation, distribution and reproduction in any medium or format, as long as you give appropriate credit to the original author(s) and the source, provide a link to the Creative Commons licence, and indicate if changes were made. The images or other third party material in this article are included in the article's Creative Commons licence, unless indicated otherwise in a credit line to the material. If material is not included in the article's Creative Commons licence and your intended use is not permitted by statutory regulation or exceeds the permitted use, you will need to obtain permission directly from the copyright holder. To view a copy of this licence, visit http://creativecommons.org/licenses/by/4.0/.

\section{References}

Bertoldo, R., \& Castro, P. (2019). From legal to normative: A combined social representations and sociocognitive approach to diagnosing cultural change triggered by new environmental laws. Culture \& Psychology, 25(3), 324-344.

Bojanowska, A., \& Zalewska, A. M. (2016). Lay understanding of happiness and the experience of wellbeing: Are some conceptions of happiness more beneficial than others? Journal of Happiness Studies, 17(2), 793-815.

Boulanger, D. (2019). Aesthetic representation and concrete dialogues across boundaries: Toward intergenerational Characterization. Culture \& Psychology, . https://doi.org/10.1177/1354067X19888198

Bourdieu, P., \& Whiteside, S. (1990). Photography: A middle-brow art. Cambridge: PolityPress.

Braun, V., \& Clarke, V. (2006). Using thematic analysis in psychology. Qualitative research in psychology, $3(2), 77-101$.

Buckingham, D. (2009). Creative'visual methods in media research: possibilities, problems and proposals. Media, Culture \& Society, 31(4), 633-652.

Buschini, F. (2016). Diffusion, propagation, propagande : et après ? L'effusion, un nouveau mode de communication médiatique pour l'étude des représentations sociales. Presentation in seminar of European Association of Social Psychology: Hommage à Serge Moscovici. Institut d'études avancées de Paris.

Carlquist, E., Ulleberg, P., Delle Fave, A., Nafstad, H. E., \& Blakar, R. M. (2017). Everyday understandings of happiness, good life, and satisfaction: Three different facets of well-being. Applied Research in Quality of Life, 12(2), 481-505. 
Chen, Y., Mark, G., Ali, S., \& Ma, X. (2017). Unpacking happiness: Lessons from smartphone photography among college students. In 2017 IEEE International Conference on Healthcare Informatics (ICHI) (pp. 429-438). IEEE.

Cortese, D. K., Szczypka, G., Emery, S., Wang, S., Hair, E., \& Vallone, D. (2018). Smoking selfies: using Instagram to explore young women's smoking behaviors. Social Media+ Society, 4(3), 2056305118790762.

Delle Fave, A., Brdar, I., Freire, T., Vella-Brodrick, D., \& Wissing, M. P. (2011). The eudaimonic and hedonic components of happiness: Qualitative and quantitative findings. Social indicators research, $100(2), 185-207$.

Delle Fave, A., Brdar, I., Wissing, M. P., Araujo, U., Castro Solano, A., Freire, T., \& Nakamura, J. (2016). Lay definitions of happiness across nations: The primacy of inner harmony and relational connectedness. Frontiers in psychology, 7, 30.

De Paola, J., Wagner, W., Pirttilä-Backman, A. M., \& Lehtonen, J. (2020). Two Sides of the Same Coin or Two Different Currencies? Representations of Happiness and Unhappiness among Finnish Women. Integrative Psychological and Behavioral Science, 1-25.

de Rosa, A.S., \& Farr, R. (2001). Icon and symbol: two sides of the coin in the investigation of social representations. In F. Buschini \& N. Kalampaliki (Eds.), Penser la vie, le social, la nature. Mélanges en hommage à Serge Moscovici(pp. 237-256). Paris: Les Editions de la Maison des Sciences de l'Homme.

Diener, E. (2009). Subjective well-being. In The science of well-being (pp. 11-58). Springer, Dordrecht.

Diener, E., \& Oishi, S. (2000). Money and happiness: Income and subjective well-being across nations. Culture and subjective well-being, 185-218.

Diller, H. J. (2008). Happy in Changing Contexts: The History of Word-use and the Metamorphoses of a Concept. Studies across Disciplines in the Humanities and Social Sciences 3. Helsinki: Helsinki Collegium for Advanced Studies. 101-130.

Duveen, G. (2008). Social actors and social groups: a return to heterogeneity in social psychology. Journal for the Theory of Social Behaviour, 38(4), 369-374.

Duveen, G., \& Moscovici, S. (2000). Social representations: Explorations in social psychology. Polity: Cambridge, Oxford.

Freitas, D. (2017). The happiness effect: How social media is driving a generation to appear perfect at any cost. Oxford University Press.

Gibbs, M., Meese, J., Arnold, M., Nansen, B., \& Carter, M. (2015). \# Funeral and Instagram: death, social media, and platform vernacular. Information, Communication \& Society, 18(3), 255-268.

Goffman, E., \& Idea, M. (1959). The Presentation of Self in Everyday Life (pp. 1-76). Garden City, NY: Anchor.

Hakoköngäs, E, Halmesvaara, O \& Sakki, I (2020). Persuasion Through Bitter Humor: Multimodal Discourse Analysis of Rhetoric in Internet Memes of Two Far-Right Groups in Finland. Social Media + Society 6(2), 1-11.

Hakoköngäs, E., \& Sakki, I. (2016). The naturalized nation: Anchoring, objectification and naturalized social representations of history. Journal of Social and Political psychology, 4(2), 646-669.

Helliwell, J. F., Layard, R., \& Sachs, J. D. (2019). World Happiness Report 2019. New York: Sustainable Development Solutions Network.

Helliwell, J. F., Layard, R., Sachs, J. D., \& De Neve, J. E. (2020). World Happiness Report 2020. New York: Sustainable Development Solutions Network.

Hurley, D. B., \& Kwon, P. (2012). Results of a study to increase savoring the moment: Differential impact on positive and negative outcomes. Journal of Happiness Studies, 13(4), 579-588.

Instagram (2020) About Instagram. Available at: https://about.instagram.com/about-us. Accessed March 31, 2020

Joffé, H. (2008). The power of visual material: Persuasion, emotion and identification. Diogenes, 55(1), 84-93.

Koo, J., \& Suh, E. (2007). Is happiness a zero-sum game? Belief in fixed amount of happiness (BIFAH) and subjective well-being. Korean Journal of Social and Personality Psychology, 21(4), 1-19.

Koski, L., \& Bäcklund, P. (2015). On the fringe: The positions of dogs in Finnish dog training culture. Society \& Animals, 23(1), 24-44.

Leaver, T., \& Highfield, T. (2018). Visualising the ends of identity: pre-birth and post-death on Instagram. Information, Communication \& Society, 21(1), 30-45.

Li, Q., \& Kim, Y. A. (2019, July). Happiness on Instagram-Content Analysis and Engagement Based on Attention Theory. In International Conference on Applied Human Factors and Ergonomics (pp. 13-20). Springer, Cham. 
Liu, L. (2004). Sensitising concept, themata and shareness: A dialogical perspective of social representations. Journal for the Theory of Social behaviour, 34(3), 249-264.

Lyubomirsky, S., King, L., \& Diener, E. (2005). The benefits of frequent positive affect: Does happiness lead to success?. Psychological bulletin, 131(6), 803.

Mackson, S. B., Brochu, P. M., \& Schneider, B. A. (2019). Instagram: Friend or foe? The application's association with psychological well-being. New Media \& Society, 21(10), 2160-2182.

Marková, I. (2000). Amédée or how to get rid of it: Social representations from a dialogical perspective. Culture \& Psychology, 6(4), 419-460.

Marková, I., \& Marková, I. (2003). Dialogicality and social representations: The dynamics of mind. Cambridge University Press.

McLean, S. A., Paxton, S. J., Wertheim, E. H., \& Masters, J. (2015). Photoshopping the selfie: Self photo editing and photo investment are associated with body dissatisfaction in adolescent girls. International Journal of Eating Disorders, 48(8), 1132-1140.

Miles, J. (2013). Instagram power: Build your brand and reach more customers with the power of pictures. New York, NY: McGraw-Hill Education.

Moloney, G., Hall, R., \& Walker, I. (2005). Social representations and themata: The construction and functioning of social knowledge about donation and transplantation. British Journal of Social Psychology, 44(3), 415-441.

Moscovici, S. (1973). Foreword. In C. Herzlich (Ed.), Health and Illness: A Social Analysis (pp. ix-xiv). London: Academic Press.

Moscovici, S. (1984). The phenomena of social representation. In R. M. Farr \& S. Moscovici (Eds.), Social representation (pp. 3-69). Cambridge, England: Cambridge University Press.

Moscovici, S. (1994). Social Representations and Pragmatic Communication. Social Science Information, 33(2), 163-177.

Moscovici, S. (2001). Why a theory of social representations? In K. Deaux \& G. Philogene (Eds.), Representations of the social (pp. 8-36). USA: Blackwell.

Moscovici, S., \& Vignaux, G. (1994). Le concept de Thêmata. In C. Guimelli (Ed.), Structures et transformations des représentations sociales. Neuchâtel, Delachaux et Niestlé.

Munzel, A., Galan, J. P., \& Meyer-Waarden, L. (2018). Getting by or getting ahead on social networking sites? The role of social capital in happiness and well-being. International Journal of Electronic Commerce, 22(2), 232-257.

Reavey, P. (2020). A Handbook of Visual Methods in Psychology: Using and Interpreting Images in Qualitative Research. Routledge.

Reinecke, L., \& Trepte, S. (2014). Authenticity and well-being on social network sites: A two-wave longitudinal study on the effects of online authenticity and the positivity bias in SNS communication. Computers in Human Behavior, 30, 95-102.

Rieger, D., \& Klimmt, C. (2019). The daily dose of digital inspiration: A multi-method exploration of meaningful communication in social media. New Media \& Society, 21(1), 97-118.

Rent a Finn (2019) Naturally happy!. Available at: https://rentafinn.com/en/. Accessed March 31, 2020

Ritland, R. (2018). Visual pleasure from motherhood: Alyssa Milano challenging the male gaze. Media, Culture \& Society, 40(8), 1281-1291.

Sakki, I. (2010). A success story or a failure. Representing the European integration in the curricula and textbooks of five countries. University of Helsinki: Department of Social Research.

Seligman, M. E. P. (2002). Authentic happiness: Using the new positive psychology to realize your potential for lasting fulfillment. New York: Free Press.

Shin, J. E., Suh, E. M., Eom, K., \& Kim, H. S. (2018). What does "happiness" prompt in your mind? Culture, word choice, and experienced happiness. Journal of Happiness Studies, 19(3), 649-662.

Suojanen, I. I. (2017). Young professionals and the pursuit of happiness at work (Doctoral dissertation, University of Edinburgh, Edinburgh, United Kingdom). Retrieved from https://era.ed.ac.uk/handl e/1842/25811

Tiidenberg, K., \& Gómez Cruz, E. (2015). Selfies, image and the re-making of the body. Body \& Society, 21(4), 77-102.

Tyrväinen, L., Ojala, A., Neuvonen, M., Borodulin, K., \& Lanki, T. (2019). Health and well-being from forests-experience from Finnish research. Santé Publique, 1(HS), 249-256.

Uchida, Y., \& Kitayama, S. (2009). Happiness and unhappiness in east and west: Themes and variations. Emotion, 9(4), 441.

Van Zyl, L. E., Hulshof, I., \& Dickens, L. R. (2019). \# NoFilter: An Online Photographic MeaningfulMoments Intervention. In Evidence-Based Positive Psychological Interventions in Multi-Cultural Contexts (pp. 57-82). Springer, Cham. 
Veenhoven, R. (2012). Cross-national differences in happiness: Cultural measurement bias or effect of culture?. International Journal of Wellbeing, 2(4).

Wagner, W. (2007). Vernacular science knowledge: its role in everyday life communication. Public Understanding of Science, 16(1), 7-22.

Zappavigna, M. (2016). Social media photography: construing subjectivity in Instagram images. Visual Communication, 15(3), 271-292.

Zieba, A. (2020). Visual representation of happiness: a sociosemiotic perspective on stock photography. Social Semiotics. https://doi.org/10.1080/10350330.2020.1788824

Publisher's Note Springer Nature remains neutral with regard to jurisdictional claims in published maps and institutional affiliations. 